\title{
ANNUAL MEAN ANALYSIS OF THE TROPICAL HEAT BALANCE AND ASSOCIATIONS WITH THE WALKER CIRCULATION
}

\author{
JOSÉ AUGUSTO PAIXÃO VEIGA ${ }^{1}$, VADLAMUDI BRAHAMANANDA RAO ${ }^{2}$ E \\ SÉRGIO HENRIQUE FRANCHITO ${ }^{2}$ \\ ${ }^{1}$ Universidade do Estado do Amazonas, Manaus, AM. \\ ${ }^{2}$ Instituto Nacional de Pesquisas Espaciais (INPE) São José dos Campos SP. \\ veiga.uea@gmail.com, vbrao@cptec.inpe.br sergio.franchito@cptec.inpe.br
}

Received May 2008 - accepted July 2010

\begin{abstract}
The present study presents an analysis of the annual mean tropical heat balance and its association with the Walker circulation (WC) using NCEP/NCAR Reanalysis data. This study shows the relative importance of diabatic data to produce vertical motion in the tropics and for the WC region. It is shown that ascending motion in the WC's upward branch is determined by the joint effect of latent heating and radiative cooling processes while infrared radiation loss is associated to sink motions on the WC's descending branch. In ascending branches of the WC vertical velocity from reanalysis is overestimated when latent heat is taken into account to drive motions. Radiative cooling is indentified as the main physical process yielding sinking motion in the WC's downward branches. In upward branches of the WC, resulting diabatic processes (latent heat release) are balanced by adiabatic expansion (due rising motions). In descending branches of the WC, there is a near balance between radiative cooling (due to longwave emission) and heating (due to sinking motions).

Keywords: Walker Circulation, Heat Balance, Tropical Circulation

RESUMO: ANÁLISE MÉDIAANUAL DO BALANÇO DE CALOR TROPICALE ASSOCIAÇÕES COM A CIRCULAÇÃO DE WALKER

Este estudo apresenta uma análise do balanço de calor anual médio da região tropical e sua associação com a Circulação de Walker (CW), a partir das reanálises do NCEP/NCAR. Este estudo mostra a importância relativa do aquecimento diabático para gerar movimentos verticais nos trópicos e na região de atuação da $\mathrm{CW}$. Os resultados mostram que o movimento ascendente nos ramos principais da $\mathrm{CW}$ é governado pelo efeito conjunto dos processos de aquecimento latente e resfriamento radiativo, enquanto que a perda de radiação infravermelha produz movimento descendente nos ramos secundários da CW. Mostra-se que o aquecimento latente força movimentos ascendentes sobre os ramos principais da $\mathrm{CW}$, todavia, a velocidade vertical observada é superestimada, se apenas o calor latente é levado em consideração para forçar os movimentos. Além disso, o resfriamento radiativo foi identificado como o principal processo físico que produz movimentos subsidentes nos ramos secundários da $\mathrm{CW}$. Nos ramos ascendentes da $\mathrm{CW}$, o aquecimento resultante entre os processos de liberação de calor latente e de resfriamento radiativo é balanceado pela expansão adiabática, enquanto que em regiões de fraca convecção (ramos secundários da $\mathrm{CW}$ ) existe um balanço aproximado entre o resfriamento radiativo (devido a emissão de ondas longas) e o aquecimento devido à compressão associado aos movimentos descendentes.
\end{abstract}

Palavras Chaves: Circulação de Walker, Balanço de Calor, Circulação Tropical 


\section{INTRODUCTION}

In the middle of the $20^{\text {th }}$ century, the Norwegian researcher Jacob Bjerknes (1969), when investigating atmospheric connections between the equatorial and northern Pacific, perceived the Southern Oscillation (SO) experienced fluctuations during years in which such connections were significant. Accordingly to Bjerknes, the SO fluctuations were a proof that the atmospheric circulation confined in equatorial regions underwent occasional variations in Pacific Ocean, especially during El Nino years. The circulation pattern, physically confined on the equatorial region, was named by Bjerknes as the Walker Circulation (WC), as an honor to the British climatologist Sir Gilbert Walker (Walker, 1923, 1924, 1928; Walker and Bliss, 1930, 1932; Walker, 1937). In such a circulation, rising motions and western winds at high levels over Indonesia and western Pacific are observed, while eastern winds at lower levels and sinking motions occur in the eastern Pacific. Bjerknes (1969) observed that the intensity of the WC substantially diminished when winds in eastern Pacific weakened, a pattern that weakens the Sea Surface Temperature (SST) gradient. Bjerknes hypothesized that the WC is not maintained under weak zonal SST gradient over equatorial Pacific. The author suggested that evaporation over warm waters could produce upward motion over western equatorial Pacific.

Cornejo-Garrido and Stone (1977) carried out a simple scale-analysis of the thermodynamic equation with the purpose of evaluating the role of diabatic heating to force the WC. In such an analysis, it was observed both radiative heating and the evaporation rate can be neglected when compared with latent heat release in forcing the WC in upward branches. Consecutively, the authors carried out a radiation budget analysis of the equatorial region and noticed that there is a quasi equilibrium between local evaporation and downward solar energy flux. Thus, evaporation rate that Bjerknes (1966) considers as one of the main dynamical components in maintaining the $\mathrm{WC}$ couldn't drive ascending motions over western Pacific, as the large amount of cloud over Indonesia attenuates the incoming radiation that would reach surface in the absence of them.

Employing an Atmospheric General Circulation Model (AGCM) to evaluate changes in the behavior of the WC under different zonal SST gradient, Chervin and Druyan (1984) showed that when the zonal SST gradient is completely absent the spatial pattern of the WC is notably greatly disturbed. The authors' main results suggest that the zonal SST gradient is important in modulating the WC, but not to drive it. Carrying out a series of numerical experiments with an AGCM to study energy and moisture budgets of the WC, Stone and Chervin (1984) showed that the correlation between precipitation and moisture convergence is higher than the relationship between precipitation and local evaporation. The results support the idea that rising motions is produced by moisture convergence instead of by evaporation as proposed by Bjerknes. Observational moisture and heat budget analysis for the WC supporting modeling results were carried out by Kayano et al. 1988, Rao et al. 1998, Veiga et al. 2005 and Veiga et al. 2009.

Pierrehumbert (1995), with the purpose to evaluate the role of the evaporation rate and cloud radiative feedbacks as main components in regulating air temperature in the tropics, developed a two box-model to represent the WC and Hadley circulation (HC). The author's model was elaborated in terms of two boxes. The first box, branded as WPA represents a Warm Pool Atmosphere. This box contains a region of net upward motions, deep convection, atmospheric heating due to latent heating and represents the ascending region of the WC. In the second box (CPA - denoting a Cold Pool Atmosphere), there is no deep convection and therefore no latent heat release. The CPA box represents a region free of convective activity, as observed over east Pacific. The results show that the air cooling over the CPA box would be yield by the horizontal moisture transport from that region toward higher temperature areas (i.e., the WPA).

Yano et al. (2002) showed that the intensity of the WC, quantified in terms of the magnitude of vertical motions, would be to a first approximation determined by subsidence-induced warming being balanced by radiative cooling over the eastern Pacific. Moreover, according to authors the descending motions are the main driving of the $\mathrm{WC}$ and the ascending movements that occur in western Pacific would be a consequence of the former.

The main purpose of this work is to evaluate the thermodynamical behavior of the WC through a careful analysis of the role of the diabatic terms in producing the motions in the tropics and for the WC domain. This kind of study can bring additional insight into the individual properties of diabatic forcing mechanisms which drive vertical motions of the WC. The paper begins with a description of datasets and methods in section 2 . Section 3 describes the results of the paper. The paper concludes with a summary and discussion of the findings in section 4 .

\section{DATA SOURCE AND METHODOLOGY}

The data that have been used in this work are provided from the National Centers for Environmental Prediction/ National Center for Atmospheric Research (NCEP/NCAR). The period of analysis consists of 13 years (1982-1994). Their resolution are $2.5^{\circ} \times 2.5^{\circ}$ degrees of latitude-longitude with 17 vertical pressure levels (1000-10 $\mathrm{hPa}$ ), see more details in Kalnay et al. (1996). The particular data used in this study are zonal and meridional wind components $(u, v)$, air temperature $(T)$, pressure vertical velocity $(\omega)$, heating rate due latent heat release $\left(\mathrm{Q}_{\mathrm{L}}\right)$, cooling rate due to long wave radiation $\left(\mathrm{Q}_{\mathrm{LW}}\right)$, 
heating rate due to shortwave radiation $\left(\mathrm{Q}_{\mathrm{Sw}}\right)$ and boundary layer heating rate $\left(\mathrm{Q}_{\mathrm{S}}-\right.$ or sensible heating). This period of study was chosen given that heating and cooling rate information are available just for those years.

To evaluate the heat balance in the tropics and associations with the Walker circulation, thermodynamic energy equation in pressure coordinates takes the following form:

$$
\begin{gathered}
\frac{\partial \bar{T}}{\partial t}+\frac{1}{a}\left(\frac{\bar{u}}{\cos \phi} \frac{\partial \bar{T}}{\partial \lambda}-\bar{v} \frac{\partial \bar{T} \cos \phi}{\partial \phi}\right)+ \\
\bar{\omega}\left(\frac{\partial \bar{T}}{\partial P}-\frac{R \bar{T}}{c_{p} P}\right)+T F=\frac{\dot{Q}}{c_{p}}
\end{gathered}
$$

where,

$$
\begin{aligned}
& T F=\frac{1}{a}\left(\frac{1}{\cos \phi} \frac{\partial u^{\prime} T^{\prime}}{\partial \lambda}+\frac{\partial v^{\prime} T^{\prime} \cos \phi}{\partial \phi}\right)+ \\
& \frac{\partial \omega^{\prime} T^{\prime}}{\partial P}-\omega^{\prime} \alpha^{\prime}
\end{aligned}
$$

and

$$
Q=Q_{R}+Q_{L}+Q_{S}+Q_{\text {cond }}+Q_{F}
$$

In the Equation 1 from left to right the terms represent, respectively, local tendency of temperature, horizontal advection of temperature, temperature change due to expansion or compression of the air, temperature change due to eddy disturbance (or transient forcing-TF), and diabatic terms $(\dot{Q})$. Quantities under bar and prime denote time mean average and deviations from the time mean averages, respectively. The term $a$ denotes the mean Earth radius, $\lambda$ and $\phi$ represent longitude and latitude, $T$ is the air temperature, $R$ is the universal gas constant, $c_{p}$ is the specific heart with constant pressure, $\alpha$ represents the specific volume $(R T / P)$ and $\dot{Q}$ is the sum of all diabatic terms considered in the Equation 3, such as: $\mathrm{Q}_{\mathrm{L}}, \mathrm{Q}_{\mathrm{LW}}$, $\mathrm{Q}_{\mathrm{SW}}, \mathrm{Q}_{\mathrm{S}}, \mathrm{Q}_{\mathrm{COND}}$ and $\mathrm{Q}_{\mathrm{F}}$. The last two terms can be obtained as residuals and in theory these values are much smaller than the others so that they are not considered in the computation of Equation 3. More details about the diabatic terms can be found out in Nigan (1994).

\section{RESULTS}

\subsection{Heat balance for the tropics and the Walker circulation}

Figure 1a-e shows, respectively, annual mean integrated values of local temperature tendency, horizontal temperature advection, the expansion/compression term, the transient forcing term, and the sum of all (residual). As can be seen from this figure, in the tropics local temperature tendency (Figure 1a), horizontal temperature advection (Figure 1b), and transient forcing terms (Figure 1d) can be neglected when compared with the expansion/compression adiabatic term (Figure 1c), which is dominant in tropical regions in terms of magnitude. Since the
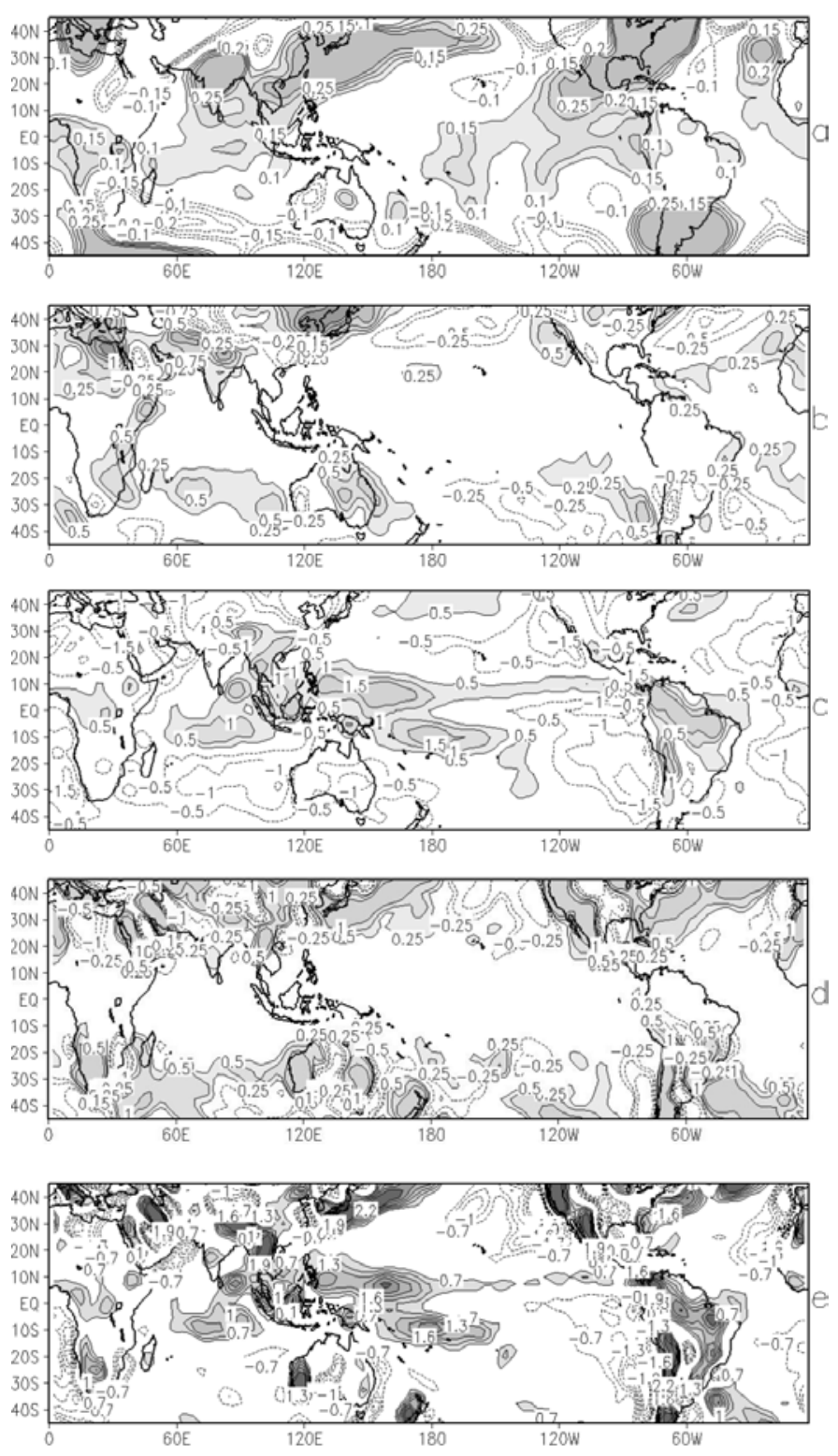

Figure 1 - Horizontal distribution of vertically integrated temperature tendency (a), horizontal temperature advection (b), expansion/ compression term $(c)$, transient forcing mechanisms ( $F$ term from Equation 1) (d), and the sum of all adiabatic terms (e) for annual mean. Units are in $10^{3} \mathrm{~K}_{\text {day }^{-1}}$. 
residual value of Equation 1 (Figure 1e) represents the sum of all diabatic processes (latent, radiative, sensible, and frictional heating rates), it can be noted that there is a near balance between the adiabatic expansion/compression term and the diabatic processes (residual), in the tropics. Based on the results of Hoskins and Karoly (1981), this heat balance pattern means if a heat source is inserted in the equatorial region upward air displacements over the source may arise to counterbalance the thermal source. However, if the thermal source is put out of tropical region other dynamical processes like horizontal advection of temperature and transient forcing arise to balance the energy source. In this case either horizontal temperature advection or transient forcing mechanisms would be equally important when compared with the expansion/compression mechanism.

Figure 2a-d depicts, respectively, the annual mean integrated values of latent heating due to moisture processes (sum of large and convective heating), radiative cooling (sum of long
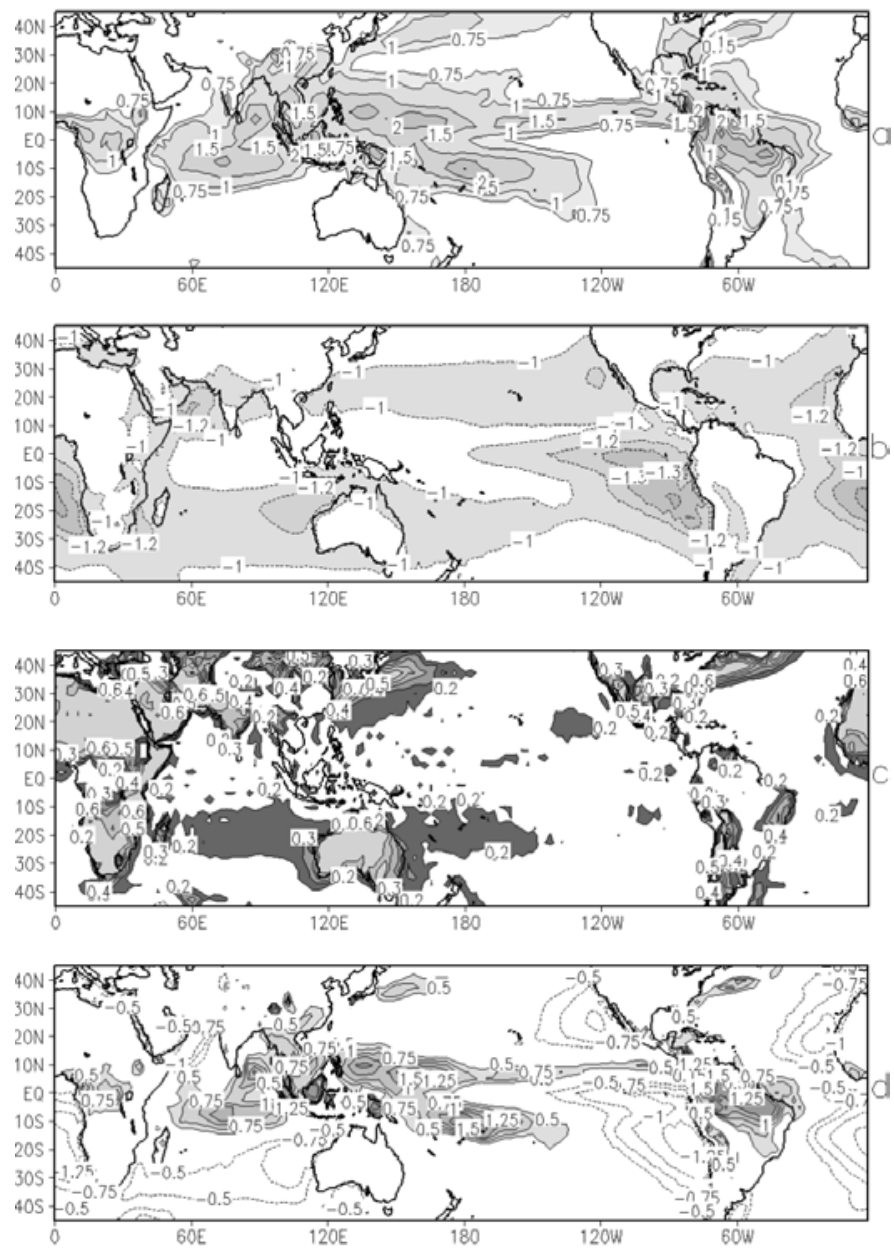

Figure 2 - Horizontal distribution of vertically integrated latent heating rate (a), radiative cooling rate (b), sensible heating rate (c), and total heating rate $\left(\mathrm{Q}_{\mathrm{L}}+\mathrm{Q}_{\mathrm{R}}+\mathrm{Q}_{\mathrm{S}}\right)(\mathrm{d})$ for annual mean. Units are in $10^{3} \mathrm{Kday}^{-1}$, excepted for sensible heating rate which unit is $10^{2} \mathrm{Kday}^{-1}$. wave cooling and short wave heating), sensible heating, and total heating (sum of all diabatic terms). It can be observed that there is a large area of latent heating over the tropics, including the three continents and a large portion of the Indian and Pacific Oceans (Figure 2a). Over the equatorial eastern Pacific and Atlantic oceans (Figure 2a) latent heating is not observed. It is related to the absence of deep convective processes, which are the main causes of latent heating release (Yanai et al., 1973).

The tropical region is characterized by a large portion of long-wave radiative cooling (not shown). Higher values of radiative cooling (negative) on the tropics, however, are found in eastern part of the oceans (Figure 2b). These higher negative values occurring in eastern tropical oceans are due to the absence of clouds, which allows the atmosphere to loss more energy (outgoing longwave radiation) in relation to other parts of the tropics where latent heating is stronger (SA and Indonesian maritime continent (IMC)). Accordingly to Bergman and Hendon (1998), the radiative cooling represents an important driving mechanism in forcing the circulation observed on subtropical heights. Over the tropics, higher values of sensible heating are observed to occur over the southern tropical part of the Indian Ocean, IMC and African continent (Figure 2c). Over the western Pacific, sensible heating is higher than in the eastern Pacific. This may be related to the difference of temperature between air and sea, which is larger in West Pacific. This forcing mechanism has less impact on the circulation even near the surface, when compared with the latent heating and radiative cooling terms (Bergman and Hendon, 1998; Tian and Ramanathan, 2002). From Figure 2d, it is noticed that over all continents and a large portion of the western Pacific and eastern Indian oceans the atmosphere is heated, mainly due latent heating release, and is cooled over the eastern Pacific and the eastern Atlantic due energy loss associated to the absence of large convective clouds.

Figure 3a-d illustrates the annual mean expansion/ compression term, latent heating rate, radiative cooling rate, latent heating plus radiative cooling rates, respectively, measured between $5^{\circ} \mathrm{N}$ and $10^{\circ} \mathrm{S}$. It is possible to note that latent heating shows significant and well-defined longitudinal and height variations, with relatively high values over IMC, Africa, and the SA continents (Figure 3b). It is also observed that there are small values of latent heating over the tropical Atlantic and western Indian Oceans. In such strongly non-convective areas, the value of SST is smaller than the adjacent air temperature. This pattern leads to a downward heat flux and inhibits large-scale vertical air displacement, thereby, limiting latent heating release to occur in the lower atmospheric levels. Thus, ascending branches of the $\mathrm{WC}$ are characterized by high values of diabatic heating due latent heat release, which must be associated with the maximum moisture convergence that is observed in this region (Rao et al. 1998; Veiga et al. 2005). The intense latent heat release which 
occurs over SA is related to both evapotranspiration (Salati and Nobre, 1991) and moisture convergence (Stone and Chervin, 1984; Veiga et al. 2005). The highest values of latent heating release observed above the mean troposphere $(500 \mathrm{hPa})$ may be related to the sublimation process which occurs in these levels.

According to Figure $3 c$, radiative cooling rates show certain variation in height and longitude where the values are highest in the downward branches of the WC (Eastern Pacific and Atlantic) and below $400 \mathrm{hPa}$. On the upward branches of the WC (SA, Africa, and IMC), and between $250 \mathrm{hPa}$ and $100 \mathrm{hPa}$ levels, smaller values of radiative cooling can be noted. Below the $100 \mathrm{hPa}$ level, the values of radiative cooling rate are higher than the values of radiative heating rate (not shown). Similar results were obtained in Bergman and Hendon (1998) which attempted to evaluate the impact of the cloud formation on the atmospheric heating profile over tropical regions. According to authors' results, regions characterized by clouds confined to lower tropospheric levels showed large values of total radiative heating, and minimum values near $100 \mathrm{hPa}$. Some factors can be the cause for the decrease of the radiative cooling with height; one of them must be due the water vapor content which decreases rapidly with height. The maximum values of the total radiative cooling was located between $400 \mathrm{hPa}$ and the surface, over regions of sinking motions, is mainly due to fewer clouds, which permits a major loss of radiative energy to the space and a consecutive cooling of the atmospheric column (Hamsey and Vicent, 1995). Another justification could be related to subsidence which would lead to long wave emissions and consequently more radiative cooling (Nigan, 1994).

Figure $3 \mathrm{~d}$ shows the sum of latent heating and radiative cooling measured between $5^{\circ} \mathrm{N}$ and $10^{\circ} \mathrm{S}$. It can be seen that radiative cooling dominates the total heating in the eastern Pacific and western Atlantic where strong cloud development is absent. Over Africa, IMC and SA latent heating dominates the total heating; however, the radiative cooling is important to reduce the effect of total heating (of the atmosphere) due the latent heating release. In these terms, the descending motions in the downward branches of the $\mathrm{WC}$ are related to radiative cooling alone, while in the upward branches of the $\mathrm{WC}$, the ascending motions are due to the joint effects of latent heating and radiative cooling, instead only due latent heating. The relationship between diabatic processes and vertical motions in the $\mathrm{WC}$ area is evaluated in the following section.

\subsection{Vertical velocity forced by diabatic heating}

Pressure vertical velocity is estimated as a function of latent heating and radiative cooling rates to evaluate the role of diabatic heating/cooling components in representing the spatial structure of the vertical motions in WC domain. In this method, each diabatic term will produce a related pressure vertical velocity with the purpose of evaluating its own importance for the WC's spatial behavior (see Veiga et al, 2009).

Figures $4 \mathrm{a}-\mathrm{d}$ show pressure vertical velocity fields obtained from NCEP/NCAR Reanalysis, computed from latent heating, radiative cooling, and from the sum of latent heating and radiative cooling, respectively. Figure $4 \mathrm{~b}$ revels that the diabatic heating due to latent heat release in the troposphere drives ascending motions in the main upward branches of the WC. However, pressure vertical velocity fields computed from
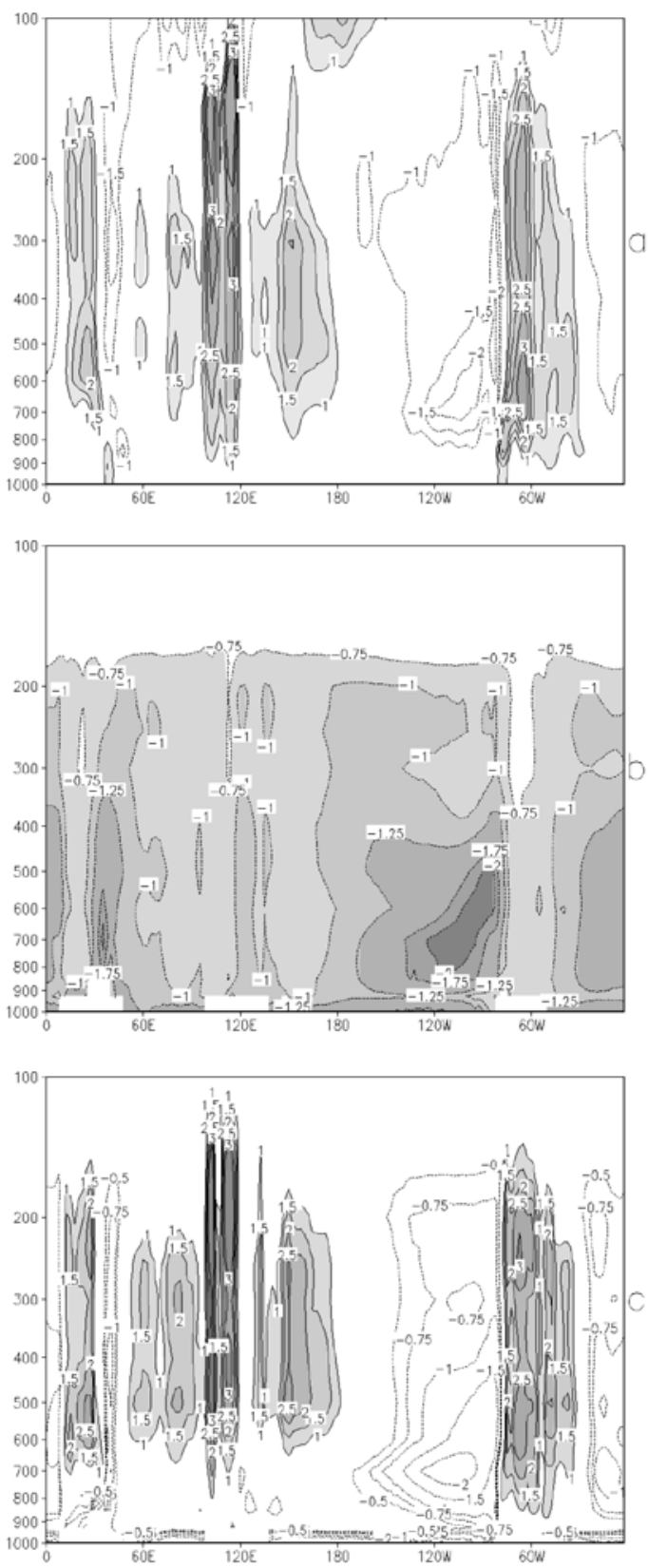

Figure 3 - Zonal vertical cross-section of latent heating rate (a), radiative cooling rate (b), and latent heating plus radiative cooling rate (c) for annual mean measured between $5^{\circ}$ and $10^{\circ} \mathrm{N}$. Units are in $\mathrm{K}_{\text {day }}{ }^{-1}$. 

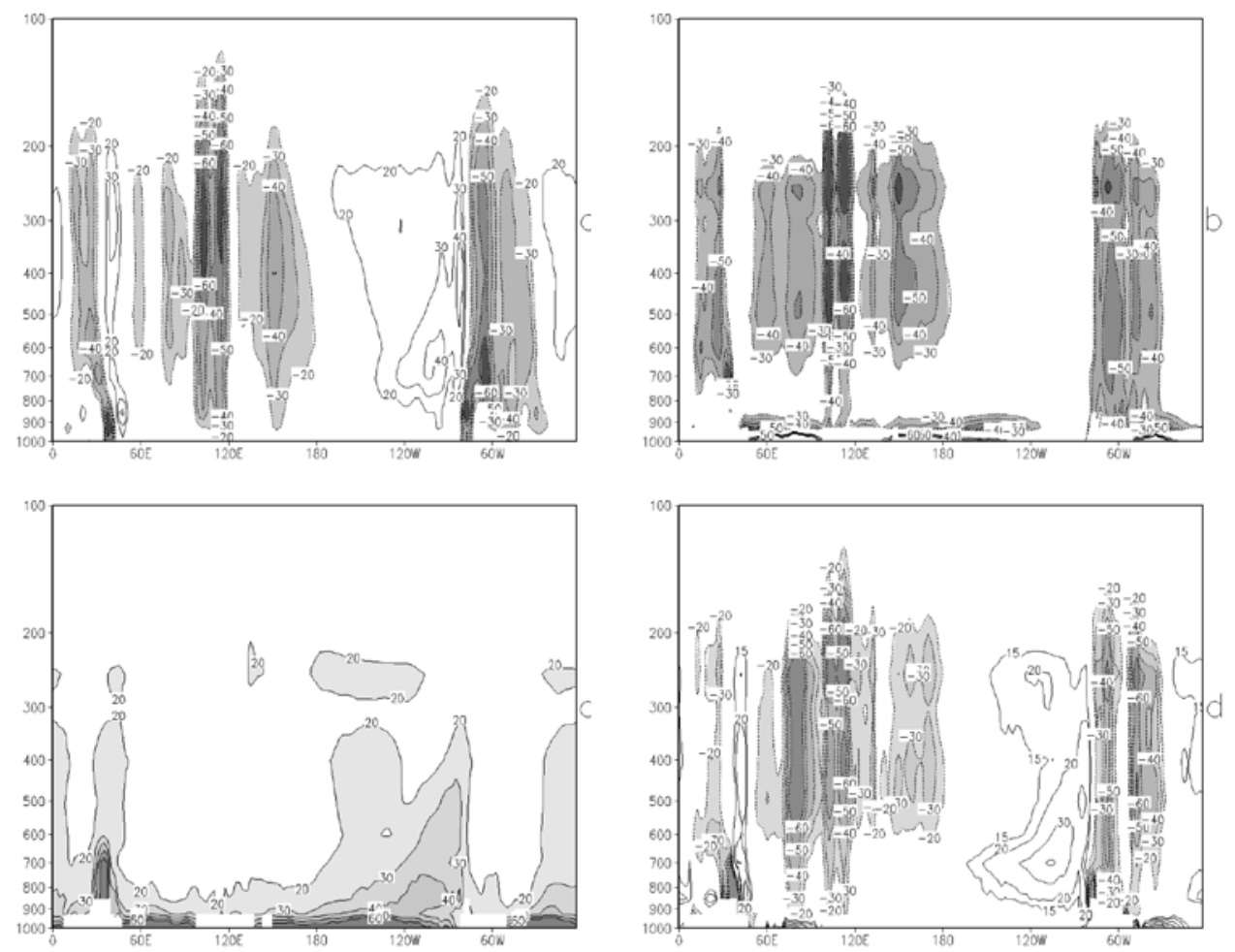

Figure 4 - Zonal vertical cross-section of vertical velocity obtained from NCEP/NCAR Reanalysis (a), vertical velocity computed from latent heating rate (b), vertical velocity computed from radiative cooling rate (c), and vertical velocity computed from the sum of latent heating rate and radiative cooling rate (d) for annual mean measured between $5^{\circ} \mathrm{N}$ and $10^{\circ} \mathrm{S}$. Units are in $h P a / d a y$.

latent heating commonly overestimate observed upward motions in these areas (Figure 4a). As radiative forcing has not taken into account in the computation of vertical velocity field, the final result shows an overestimated observed field. Maximum and minimum values of the pressure vertical velocity, however, are well represented. As can be seen from Figure $4 b$, the latent heating process causes no impact over regions of sinking motion (eastern Pacific). This result suggests that the descending branch of the WC are dominated by others factors.

The pressure vertical velocity field estimated from radiative cooling is showed in Figure 4c. This figure shows that the radiative cooling is the principal maintainer of the sinking motions in the WC zone (eastern Pacific). The magnitudes of the pressure vertical velocity obtained from the NCEP/NCAR Reanalysis (Figure 4a) are well represented by the pressure vertical velocity forced by radiative cooling process. For instance, $Q_{R}$ forces intense sinking motions near surface in the eastern Pacific and western Indian Oceans. This occurrence must be related to the fact that sensible heating was not considered in this computation which provides ascending motions near the surface (not shown). Pressure vertical velocity for the joint effect of latent and radiative processes can be seen from Figure 4d. This Figure shows that the maintenance of the WC in its rising branches is due to the joint effect of diabatic cooling and latent heating, while descending motions in downward branch of the $\mathrm{WC}$ are associated with energy loss by radiative processes. Over the upward branches of the WC, the resultant effect between latent and radiative processes is in near balance with the cooling due to adiabatic expansion. On the other hand, in downward branches of the WC, there is a near balance between radiative cooling and adiabatic heating due to subsidence (compression).

Figures 5a-b shows the vertical cross-section of pressure vertical velocity computed from diabatic terms for the upward and downward branches of the WC, respectively. In the upward branch of the WC, the main driver of ascending motions $\left(\omega_{\mathrm{L}}\right)$ is the latent heat release due clouds formation, while radiative cooling forces descending motions $\left(\omega_{R}\right)$. It can be seen that the joint effect of radiative and latent processes forces a more realistic vertical ascent motions $\left(\omega_{\mathrm{L}+\mathrm{R}}\right)$ then just latent heating alone provides $\left(\omega_{\mathrm{L}}\right)$ in the upward branch of the WC (Figure 5a). Pressure vertical velocity computed from latent heating rate overestimates observed vertical velocity $\left(\omega_{\mathrm{REA}}\right)$ above $600 \mathrm{hPa}$ and provides a maximum between 200-300 hPa layer. More realistic ascent motions is obtained when radiative cooling rate is considered $\left(\omega_{\mathrm{L}+\mathrm{R}}\right)$, however, the joint effect underestimates $\omega_{\text {REA }}$ below the $600 \mathrm{hPa}$ level.

In the downward branch of the WC, descending motion is strongly forced by radiative processes instead due the joint 

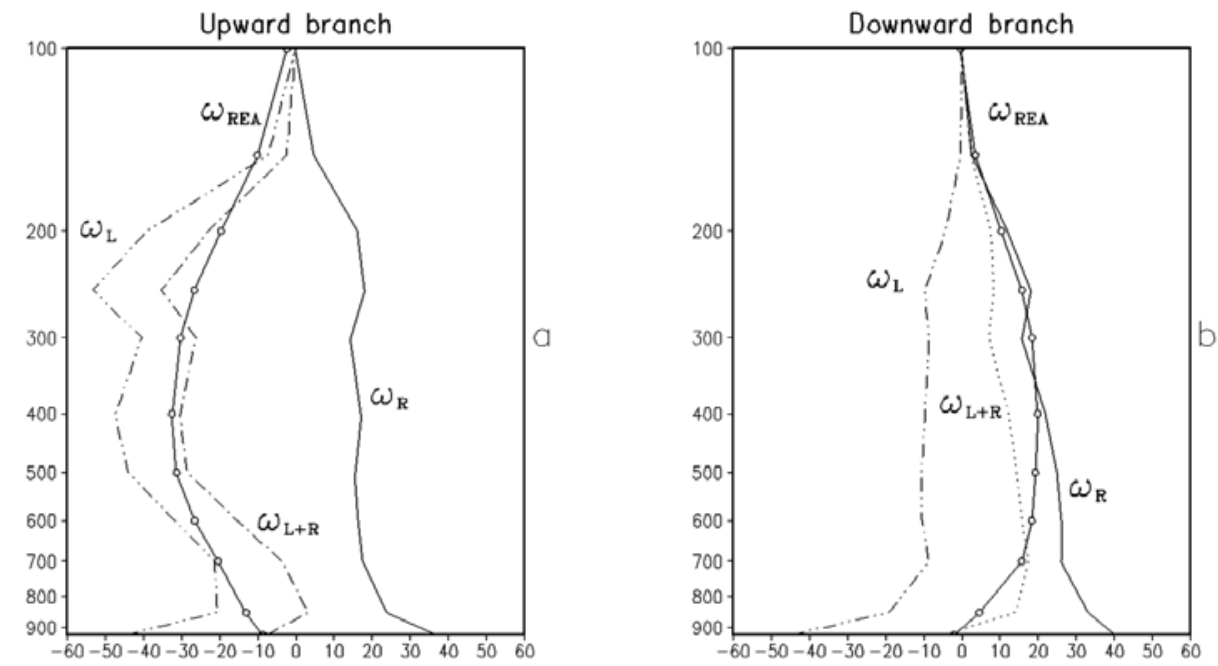

Figure 5 - : Pressure mean annual vertical velocity from NCEP/NCAR Reanalysis ( $\omega$ REA), computed from latent heating $(\omega \mathrm{L})$, radiative cooling $(\omega \mathrm{R})$, and from the sum of $\omega \mathrm{L}$ and $\omega \mathrm{R}(\omega \mathrm{L}+\mathrm{R})$ for ascent (a) $\left(100^{\circ}-170^{\circ} \mathrm{W}\right.$ and $\left.-5^{\circ} \mathrm{N}-10^{\circ} \mathrm{S}\right)$ and descent $\left(175^{\circ} \mathrm{W}-90^{\circ} \mathrm{E}\right.$ and $\left.-5^{\circ} \mathrm{N}-10^{\circ} \mathrm{S}\right)(\mathrm{b})$ regions of the Walker circulation. Units are in $\mathrm{hPa}$ /day.

effect (latent plus radiative arte), see Figure 5b. Latent heating is nearly absent in downward branch where radiative cooling is the dominant process related to sinking motion. The fact that radiative cooling underestimates vertical velocity below 600 $h P a$ may be related to the absence of boundary layer heating in the computation of $\left(\omega_{R}\right)$.

A schematic diagram of the heat balance for the WC is shown in Figure 6. From this figure it can be seen that ascending motions in upward branches of the WC is driven by both effect of latent heating and radiative cooling, where this heating process is in near balance with the cooling by expansion (non-exactbalance). In other hand, sinking motion in downward branch

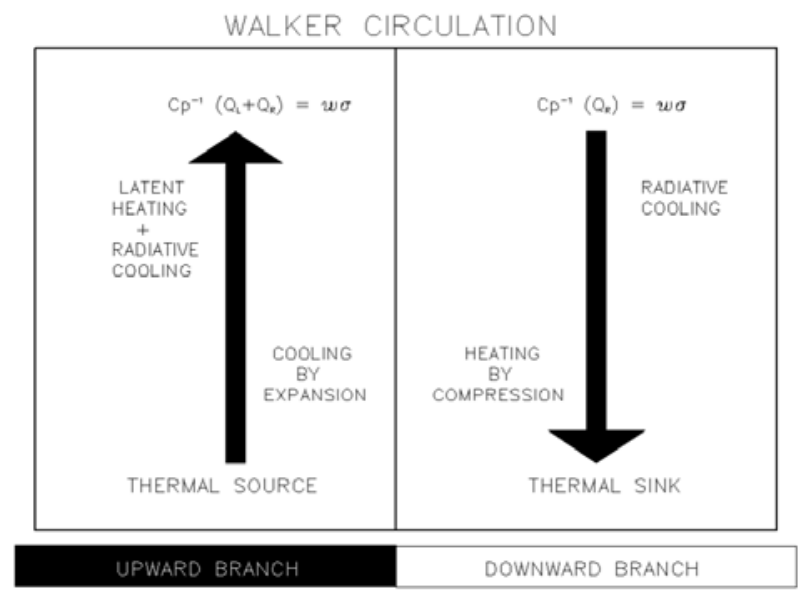

Figure 6 - Schematic diagram of the Walker circulation heat balance. of the WC are related to the radiative cooling mainly due the loss of longwave radiation. Radiative cooling in the downward branch is balanced by atmospheric heating due to adiabatic compression.

\section{CONCLUDING REMARKS}

This study investigates the annual mean heat balance of the tropics and associations with WC from NCEP/NCAR Reanalysis data. To evaluate the main drivers of vertical motions in the tropics and for the WC domain, diabatic data were used to calculate the pressure vertical velocity. Moreover, it was possible to separate the individual effects of radiative cooling and latent heating in forcing vertical motions.

The results showed that sensible and latent heating are stronger over continental regions, while radiative cooling have higher negative values over tropical eastern oceans. Over the western Pacific, sensible heating is higher than in the eastern region. Higher values of latent heating and lower values of radiative cooling are found to occur in the upward branches of the WC, while highest negative (lowest) values of radiative cooling (latent heating) are found to occur in the downward branches of the WC (Eastern Pacific and Atlantic Oceans). In regions of weak convection, the radiative cooling dominates the total diabatic heating rate.

An analysis of each diabatic terms revealed that regions such as Africa, South America, and IMC, which are regions with net rising motions, are characterized by strong diabatic heating due, mainly, to latent heat release. This heating over regions of 
convective activity of the WC is balanced by the adiabatic cooling during expansion and by the radiative cooling. Regions with net sinking motions such as in the eastern Atlantic and Pacific Oceans, are characterized by intense radiative cooling, mainly due infrared radiation emission. In this way, the radiative cooling due to the loss of infrared radiation is, approximately, balanced by the adiabatic heating during the air compression process.

A quantification of the relative contributions of the diabatic terms in forcing vertical velocity in the WC domain revealed that latent heating is the main tropospheric driver of ascending motions in upward branches of the WC. However, values of computed pressure vertical velocity in WC's upward branch overestimates observed values if latent heating is considered as the one forcing mechanism. Moreover, if the resultant effect between radiative cooling and latent heating are considered in re-computing pressure vertical velocity over the upward branch domain, more realistic vertical motions are reached. In the downward branch of the $\mathrm{WC}$, radiative cooling process is the main factor in producing descending motions above $600 h P a$ level.

A simplified scheme of the WC thermodynamics (Figure 6) shows that the main branch of the WC is characterized by a region with net of rising motions and robust convective activities, and, as a consequence, latent heat release. The net rising motions are due to the imbalance between radiative cooling and latent heating. Moreover, it is necessary to point out that, it is this balance whose determines the intensity of the vertical motions over the main branch of the WC.

\section{REFERENCES}

BERGMAN, J. W. AND H. H. HENDON, Calculating monthly radiative fluxes and heating rates from monthly cloud observations, Jour. Atmos. Sci. 68, 3471-3491, 1998.

BJERKNES, J., Atmospheric teleconnections from the equatorial Pacific, Mon. Wea. Rev. 97, 163-172, 1969.

CHERVIN, R. M. AND L. M. DRUYAN, The influence of ocean surface temperature gradient and continentality on the Walker circulation, Mon. Wea. Rev. 112, 1510-1523, 1984.

CORNEJO-GARRIDO, A. G. AND P. H. STONE, On the heat balance of the Walker Circulation, Jour. Atmos. Sci. 34, 1155-1162, 1977.

HAMSEY, G. P. AND D. G. VICENT, Computation of vertical profiles of longwave radiative cooling over the equatorial Pacific, Jour. Atmos. Sci. 52, 1555-1572, 1995.

HOSKINS, B. J.; KAROLY, D. J. The steady linear response of a spherical atmosphere to thermal and oceanographic forcing. Jour. Atmos. Sci. 38, 1179-1196, 1981.

KALNAY, E. ET AL., The NCEP/NCAR 40-year reanalysis project, Bull. Ame. Meteo. Soc. 47, 437-471, 1996.
KAYANO, M. T.; RAO V. B. AND A. D. MOURA, Tropical circulation and associated rainfall anomalies during two contrasting years, Jour. Climatol. 41, 477-488, 1988.

NIGAN, S., On the dynamical basis for the Asian summer monsoon rainfall-El Nino relationship, Journal Climate 7, 1750-1771, 1994.

PIERREHUMBERT, R. T., Thermostats, radiator fins, and the local runaway greenhouse, Jour. Atmos. Sci.. 103, 17841806, 1995.

RAO, V. B.; CHAPA, S. R. AND I. F. A. CAVALCANTI, Moiture budget in the tropics and the Walker circulation, Jour. Geophy. Res. 103, 13713-13728, 1998.

SALATI, E; NOBRE, C. A. Possible climatic impacts of tropical deforestation. Climate Change. 101, 26539-26551, 1991.

STONE, P. H. AND R. M. CHERVIN, The influence of ocean temperature gradient and continentality on the Walker circulation. Part II: Prescribed global changes, Mon. Wea. Rev. 112, 1524-1543, 1984.

TIAN, B; RAMANATHAN, V. Role of tropical clouds in surface and atmospheric energy budget. Journal of Climate. 15, 296-305, 2002.

VEIGA, J. A. P.; RAO, V. B. and S. H. FRANCHITO, Heat and moisture budgets of the Walker circulation and associated rainfall anomalies during El Nino events, Inter. Journ. Climatol. 25, 193-213, 2005.

VEIGA, J. A. P.; RAO, V. B. and S. H. FRANCHITO, On the initiation of the Walker circulation, Revista Brasileira de Meteorologia. 24, 63-68, 2009.

WALKER, G. T., Correlation in seasonal variations of weather, VIII: A preliminary study of world weather, Memoirs of the Indian Meteorological Department 24, 75-131, 1923.

WALKER, G. T., Correlation in seasonal variations of weather, IX: A further study of world weather, Memoirs of the Indian Meteorological Department 24, 275-332, 1924.

WALKER, G. T., World weather III, Memoirs of the Indian Meteorological Department 2, 97-103, 1928.

WALKER, G. T. AND E. W. BLISS, World weather IV, Memoirs of the Royal Meteorologica Society 3, 81-95, 1930.

WALKER, G. T. AND E. W. BLISS, World weather V, Memoirs of the Royal Meteorological Society 4, 53-84, 1932.

WALKER, G. T., World weather VI, Memoirs of the Royal Meteorological Society 2, 119-139, 1937.

YANAI, M.; ESBENSEN, S.; CHU, J. H. Determination of bulk properties of tropical cloud clusters from large-scale heat and moisture budgets. J. Atm. Sci., 30, 611-627, 1973.

YANO, J. I.; GRABOWSKI, W. W. AND M. W. Moncrieff, Mean-state convective circulation over large-scale tropical SST gradients, Jour. Atmos. Sci.. 59, 1578-1592, 2002. 